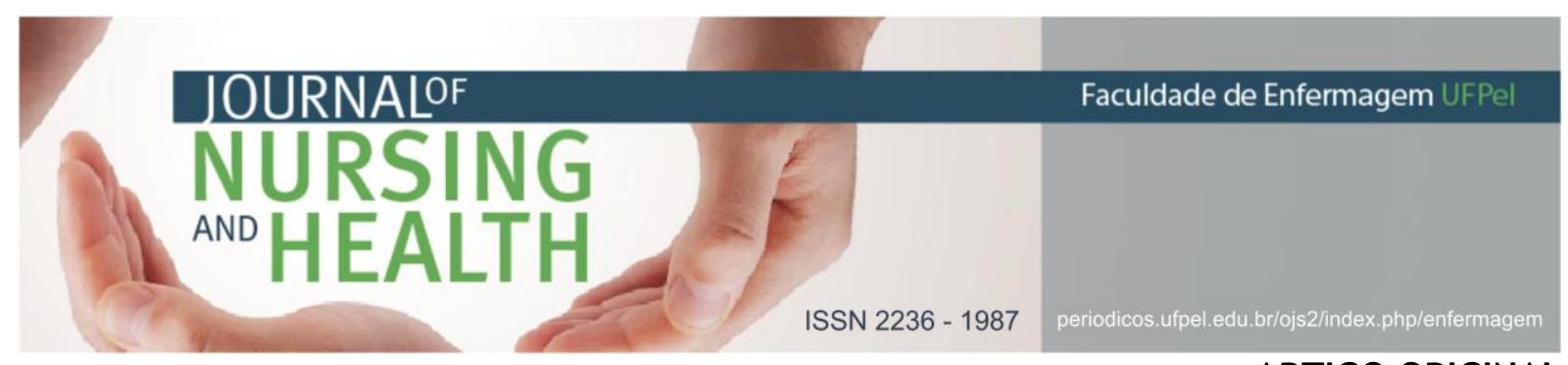

ARTIGO ORIGINAL

\title{
A percepção de mulheres sobre o exame preventivo de câncer uterino e os seus resultados
}

\section{The perception of women about the preventive examination of uterine cancer and its results}

\section{La percepción de las mujeres sobre el examen preventivo de cáncer uterino y sus resultados}

Sebold, Luciara Fabiane1; Suave, Suelen²; Girondi, Juliana Balbinot Reis ${ }^{3}$; Kempfer, Silvana Silveira4; Echevarría-Guanilo, Maria Elena ${ }^{5}$

\section{RESUMO}

Objetivo: analisar a compreensão das mulheres ao receberem o resultado do exame orientado pela enfermeira. Métodos: pesquisa de abordagem qualitativa, Convergente Assistencial. Foi desenvolvida com 14 mulheres, usuárias da Estratégia Saúde da Família, de um município de Santa Catarina, Brasil, em outubro de 2011. Utilizou-se entrevista semiestruturada e a análise de conteúdo Resultados: as mulheres que não realizavam o exame preventivo com periodicidade tinham menos compreensão dos resultados que daquelas que realizavam o exame anualmente. A atuação do enfermeiro nas ações educativas é de extrema importância, orientando sobre prevenção, esclarecendo dúvidas e divulgando informações adequadas. Considerações finais: as mulheres que adquirem confiança no profissional enfermeiro entendem que esse é qualificado para realizar a coleta e a entrega do resultado do exame. Descritores: Enfermagem; Saúde da mulher; Teste de papanicolaou.

\begin{abstract}
Objective: to analyze the understanding of women to receive the test results driven by the nurse. Methods: quantitative and Convergent Care Research, developed with 14 women, users of the Family Health Strategy, in a city of Santa Catarina in October 2011. A semistructured interview and content analysis were used. Results: the women who did not perform the screening test at intervals had less understanding of the results of those who underwent the test annually. The acting of the nurse in educational activities is extremely important, advising on prevention, answering questions and disseminating appropriate information. Final Considerations: women who gain confidence in the nurse understands that it is qualified to carry out the collection from start to delivery of results.

Descriptors: Nursing; Women's health; Papanicolaou test.
\end{abstract}

\footnotetext{
1 Enfermeira. Doutora em Enfermagem. Docente do Departamento de Enfermagem do Programa de PósGraduação em Gestão do Cuidado em Enfermagem da Universidade Federal de Santa Catarina, Florianópolis, Santa Catarina, Brasil. E-mail: fabiane.sebold@ufsc.br

2 Enfermeira da Estratégia de Saúde da Família no município de Dona Emma. Santa Catarina, Santa Catarina, Brasil. E-mail: suelensuave@hotmail.com

3 Enfermeira. Doutora em Enfermagem. Docente do Departamento de Enfermagem do Programa de PósGraduação em Gestão do Cuidado em Enfermagem da Universidade Federal de Santa Catarina, Florianópolis, Santa Catarina, Brasil. E-mail: juliana.balbinot@ufsc.br

${ }^{4}$ Enfermeira. Doutora em Enfermagem. Docente do Departamento de Enfermagem da Universidade Federal de Santa Catarina, Florianópolis, Santa Catarina, Brasil. E-mail: silvana.kempfer@ufsc.br

${ }^{5}$ Enfermeira. Doutora em Enfermagem. Docente do Departamento de Enfermagem da Universidade Federal de Santa Catarina, Florianópolis, Santa Catarina, Brasil. E-mail: elena_meeg@hotmail.com
} 


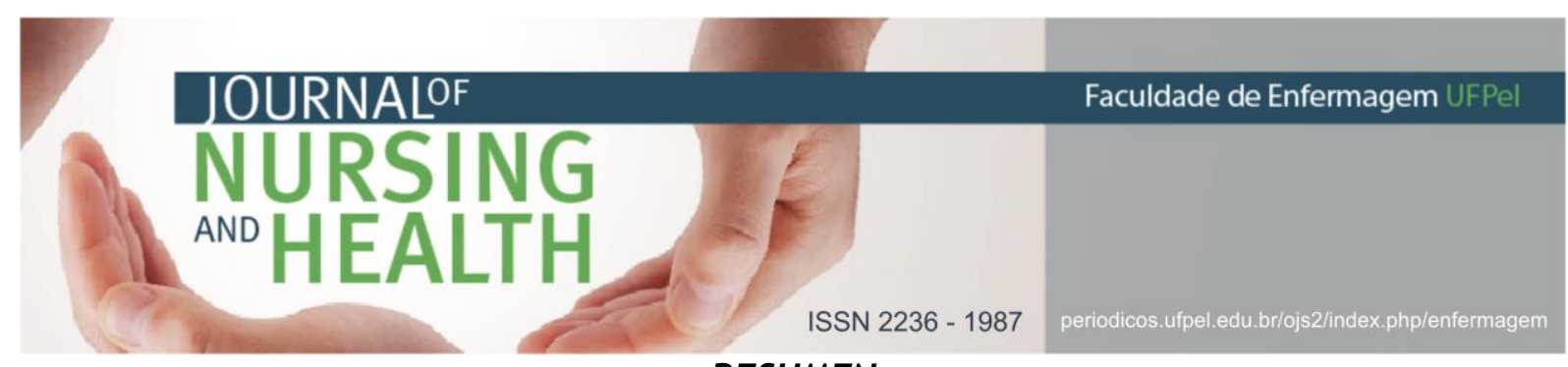

RESUMEN

Objetivo: analizar la comprensión de las mujeres sobre los resultados de las pruebas conducidas por la enfermera. Métodos: investigación cuantitativa, Convergente Asistencial, con 14 mujeres, usuarias de una Estrategia de Salud de la Familia, de un municipio de Santa Catarina, en octubre de 2011. Se realizó una entrevista semiestructurada y análisis de contenido. Resultados: las mujeres que no realizan la prueba de detección periódicamente tenían menos conocimiento de los resultados que aquellas que realizaban la prueba anualmente. La actuación del enfermero en las actividades educativas es de extrema importancia, asesorando sobre prevención, esclareciendo dudas y realizando la difusión de información adecuada. Consideraciones finales: las mujeres con mayor confianza en el enfermero comprenden que está calificada para realizar el proceso desde la asesoría y recolección de las muestras hasta la entrega de los resultados.

Descriptores: Enfermería; Salud de la mujer; Prueba de papanicolaou.

\section{INTRODUÇÃO}

O câncer do colo uterino (CCU) é uma das neoplasias de maior possibilidade de prevenção. ${ }^{1}$ Nos últimos anos, sua incidência vem aumentando dramaticamente, passando a representar grande preocupação na saúde pública. Há necessidade de ampliação e aprimoramento do atendimento, por parte dos profissionais de saúde, assim como da melhora de estratégias para o acesso aos serviços e realização do exame preventivo, conhecido como Papanicolau ou colpocitopatológico. ${ }^{2}$

No mundo, o CCU é responsável por 265 mil óbitos/ano e é a quarta causa mais frequente de morte por câncer entre mulheres. ${ }^{3}$ No Brasil, em 2016, foram esperados 16.340 casos novos, com um risco estimado de 15,85 casos a cada 100 mil mulheres. É a terceira localização primária de incidência e de mortalidade por câncer em mulheres no país, excluído por pele, não melanoma. ${ }^{4}$

Os programas de detecção e controle do CCU incluem três níveis: a prevenção primária, a prevenção secundária e a prevenção terciária. A primária está baseada na promoção da saúde para redução da exposição das mulheres aos fatores de risco para o câncer. A secundária é o conjunto de ações que promovam o diagnóstico precoce da doença e o seu tratamento, a chance de cura e redução da mortalidade por câncer. $\mathrm{E}$ a terciaria engloba as atividades para reabilitação e prevenção. Contudo, o controle do câncer depende essencialmente de ações de promoção da saúde, proteção e diagnóstico precoce. ${ }^{5}$

A realização do exame preventivo tem entre seus principais objetivos a detecção precoce do CCU. Os serviços de saúde, tais como, as Unidades Básicas de Saúde (UBS), devem aprimorar sistemas de registro, a qualificação das equipes e o aumento de insumos e materiais necessários para a realização do exame preventivo. ${ }^{6}$ Além de reforçar com os profissionais da saúde a importância, não apenas da entrega dos resultados, mas também, a interpretação dos mesmos para que as mulheres entendam o que significam.

Nesse sentido, o trabalho do enfermeiro, na Estratégia de Saúde da Família, volta-se também para a sensibilização das mulheres sobre a prevenção e o diagnóstico precoce do 


\section{JOURNALOF \\ NURSING \\ AND HEALTH}

ISSN 2236 - 1987

CCU, principalmente, por meio da educação em saúde. ${ }^{7-8}$

A falta de orientação representa um grande obstáculo do processo de detecção precoce do CCU e para o não retorno das mulheres e acesso aos resultados, ou a falta de compreensão dos resultados apresentados em seus exames. ${ }^{7}$ Fatos que dificulta 0 acompanhamento, a integralidade e a continuidade da assistência, e a intervenção em fases precoces da doença. Nesse contexto, surgiu a seguinte questão de pesquisa: Qual a compreensão que as mulheres têm ao receberem $o$ resultado do exame preventivo, orientado pela enfermeira? Definindo-se como objetivo da pesquisa: analisar a compreensão das mulheres sobre o resultado e o exame preventivo para câncer de colo uterino.

\section{MATERIAIS E MÉTODO}

Estudo qualitativo de abordagem convergente assistencial.8 Realizado em um município de Santa Catarina, num centro de saúde da periferia, na equipe de saúde da família. Atualmente possui 1.772 famílias cadastradas.

Os dados foram coletados em outubro de 2011 com 14 mulheres que retornaram ao centro de saúde para buscarem 0 resultado do exame preventivo, após terem sido contatadas via telefone. A idade das mulheres entrevistadas variou entre 18 a 55 anos de idade. 0 grau de escolaridade que predominou foi 0 ensino fundamental.

As mulheres que, após contato telefônico, não retornaram ao centro de saúde para receber os resultados não fizeram parte do estudo.

No mês de setembro, foram realizadas 36 coletas para exames preventivos, e no mês de outubro, após várias tentativas de contato telefônico, apenas 14 mulheres retornaram para buscar seus resultados. Todas as participantes do estudo assinaram o Termo de Consentimento Livre e Esclarecido.

Foi realizada entrevista semiestruturada, seguindo as seguintes questões norteadoras: Com que frequência você realiza o exame preventivo?; Por que você acha importante a realização do exame preventivo?; Me fale o que você sabe sobre o exame preventivo; fale sobre suas expectativas quanto ao resultado do exame.

As entrevistas foram gravadas em áudio, transcritas e analisadas por meio da técnica de análise de conteúdo, modalidade temática. 9 Seguiram-se três passos: pré-análise e fase de organização, que incluiu a transcrição das falas, organização das informações transcritas e leitura flutuante do material transcrito; exploração do material e tratamento dos resultados, consistiu na leitura atenta voltada à identificação de aspectos marcantes na fala dos participantes, permitindo a categorização dos dados; e inferência e interpretação, que consistiu na interpretação das entrevistas.

0 estudo foi aprovado pelo Comitê de Ética em Pesquisa do Centro Universitário para o Desenvolvimento do Alto Vale do Itajaí - UNIDAVI, sob protocolo $\mathrm{n}^{\circ} 992 / 2012$ e pela 


\section{NURSING \\ AND \\ HEALTH}

instituição em estudo. Foram respeitados os preceitos éticos conforme a Resolução 466/12 do Conselho Nacional de Saúde.10

\section{RESULTADOS}

Do processo de análise, surgiram três temas centrais, apresentados na sequência: A frequência da realização do exame preventivo; O conhecimento das mulheres sobre 0 exame preventivo; e, Entendimentos acerca do resultado do exame.

\section{A frequência da realização do exame preventivo}

As mulheres entrevistadas relataram realizar periodicamente 0 exame preventivo, porém, a frequência da realização do mesmo foi variada. Algumas participantes relataram ter realizado o exame preventivo pela primeira vez, assim como estar buscando os resultados do exame preventivo pela primeira vez.

Na verdade, é a primeira vez que fiz o exame (VSR).

Esse foi meu primeiro exame, comecei a ter relações agora (LMGR).

Outras mulheres revelaram ter por rotina a realização anual do exame, contudo, uma relatou não ter realizado em decorrência de não ter conseguido consulta.

Agora faço uma vez por ano (IAS).

Sempre fiz uma vez por ano (AS).

Anualmente. Mas ano passado eu pulei, não fiz, eu sempre faço
ISSN 2236 - 1987

[...] daí ano passado não consegui consulta lá, daí não fiz, e esse ano fiz aqui (MJQ).

Entretanto, outras compartilharam que a realização do exame preventivo era esporádica, sendo as razões apontadas:

Eu faço só quando tenho vontade. $A h$, cada dois ou três anos (ELS).

Antigamente antes de ter filho fazia todos os anos, mas depois que tive meu filho, fiz mais umas duas vezes (RT).

Eu acho que faz uns três anos que não faço, e não faço com frequência, porque uma vez eu fiz, teve um resultado bom e daí a gente acaba relaxando porque acha que sempre vai estar bom, não vê a importância [...] eu faço a cada dois, três anos ou quando aparece alguma complicação, infecção, algum corrimento ou acontece uma candidíase, ali que me preocupo, enquanto percebo que está tudo certo acabo não fazendo (SF).

Algumas mulheres relataram ter conhecimento sobre a importância, mas outras, mesmo desconhecendo o que é o preventivo, identificam a seriedade da sua realização para detectar não só o câncer, mas outras doenças infecciosas. As mulheres relataram fazer o exame preventivo com 0 intuito de se proteger e, consequentemente, ter uma qualidade de vida.

Caso tenha algum problema no colo do útero já previne agora de início, assim que eu aprendi, 


\section{ISSN 2236 - 1987}

precisamos cortar o mal pela raiz, se tiver alguma coisa trato agora para no futuro mais próximo não ter problema (VSR).

É importante para não pegar um câncer de útero, essas coisas assim, prevenir inflamações [...] (CGS).

Eu sei da importância, porque fazendo ele tu consegues encontrar, consegue diagnosticar vários problemas através do preventivo, ele é a melhor prevenção para uma pequena infecção ou até para um possível caso de câncer. É uma forma de remediar, é uma forma fácil, rápida, de graça, pois o posto fornece todo esse serviço, é de livre acesso [...] mas as mulheres não procuram. Eu, por exemplo (SF).

Os sentimentos de constrangimento e vergonha na realização do exame preventivo foram relatados pelas mulheres, como sendo um dos motivos pelos quais a mesmas deixam de realizar seu exame.

Exame serve para saber o que a gente tem, eu sei que é muito importante fazer, mas eu tenho vergonha, daí eu deixo de fazer (ELS).

[...] é muito constrangedor fazer, porque assim, já aconteceu de fazer preventivo e a enfermeira me machucar, sabe, até porque é uma coisa constrangedora para mulher [...] (SF).

A mulheres relatam que realizar o exame é uma forma de prevenção do
CCU, o reconhecendo como o melhor remédio. Assim, nas falas identifica-se com clareza porque as mesmas comparecem na Estratégia de Saúde da Família (ESF) para fazerem o exame preventivo. Entretanto, expressam com clareza o receio em descobrir que algo não está certo com sua saúde.

Para identificar problemas, vamos supor a pessoa tem algum problema e se identificando a tempo o risco vai ser menor (LSS).

[...] é uma prevenção, por causa do câncer de colo de útero [...] pelo menos uma vez por ano [...] fazer o preventivo. É uma forma de descobrir e tratar logo (LMGR).

\section{0 conhecimento das mulheres sobre o exame preventivo}

Ao analisar as falas das mulheres, percebeu-se que as mesmas sabiam da importância do exame, porém, não sabiam explicar com clareza a forma como este era realizado. Entretanto, em relação a seus benefícios, cada uma, da sua forma, sabia que era para detectar o CCU.

[...] sei que é para prevenir complicações no colo do útero, ovário, e essas coisas por dentro da mulher e por causa das inflamações (IAS).

[...] é feito uma vez por ano, [...] para diagnosticar algum problema de saúde [...] um câncer, e no dia da coleta é muito tranquilo, eu sempre faço aqui no posto com elas (enfermeiras) e elas atendem muito bem (LSS). 
Sei que elas procuram o câncer, e a gente faz por prevenção, não sei mais nada. [...] vocês fazem coleta de material [...] para vocês tudo tem uns nomes especiais [...]. É muito desconfortável fazer isso (MJQ).

As mulheres possuem muitas informações sobre o exame preventivo. Algumas mulheres conhecem partes do processo da coleta das amostras, porém, desconhecem o objetivo específico do exame.

Antes de fazer o exame, preciso ficar três dias sem ter relações, isso que eles falavam onde eu morava (Recife), só isso que sei. [...] lá na minha terra eles não coletavam de dentro do útero porque ela nunca usou essa escovinha. [...] a enfermeira fazia o exame e depois de 40 dias podia ir buscar, ela era chamada enfermeira da prevenção, porque trabalhava só com essas coisas mesmo, e se precisasse ela já passava o remédio também, o exame era feito no hospital não no postinho (CGS).

[...] a gente se posiciona na maca e ela coleta o material de dentro do colo do útero, com uma escovinha e com uma espátula (LMGR).

\section{Entendimentos acerca do resultado do exame}

As respostas sobre 0 entendimento do resultado do exame preventivo para mulheres variaram, envolvendo compreensão do resultado, assim como o descaso das mesmas.
Além disso, chamou a atenção das mulheres as alterações benignas relacionadas aos diagnósticos de infecção.

As entrevistadas manifestaram a grande dificuldade para compreender os resultados do exame, já que os mesmos eram apresentados a partir do laudo médico, os quais são descritos em uma linguagem científica, dificultando a interpretação por parte das mulheres, deixando-as com dúvidas e medos.

Aqui está marcado satisfatória, que não deu nenhuma alteração e que está tudo bem. Mas nessas palavras não sei explicar certinho (LSS).

[...] pelo que estou lendo aqui tenho uma inflamação no útero. $\mathrm{E}$ o resto deu negativo. 0 certo deveria ter outra palavra ali, porque é difícil de entender, e sabe, fiquei preocupada porque de uma inflamação pode vir muitas coisas. Mas agora está esclarecido e foi bem explicado (NPS).

O que eu sei, que eu entendo é que, essa inflamação que aparece escrito aqui, quando vem, dizem que isso é normal, mas não sei por que $(A S)$.

Sim, está dizendo que a coleta foi satisfatória, escamoso glandular para mim é nada, inflamação, que dá em todos os exames porque isso é da mulher mesmo, e negativo para neoplasias, não tenho câncer (MJQ). 


\section{JOURNALOF \\ NURSING \\ ANO HEALTH \\ ISSN 2236 - 1987}

A falta de divulgação e o não conhecimento do exame gera 0 descaso. A divulgação incipiente da importância do exame preventivo de CCU ainda é um desafio para os profissionais da saúde e as mulheres. 0 não entendimento do exame termina contribuindo com a opção das mulheres por não fazer.

[...] não sei o que quer dizer esse escamoso glandular, acabo não dando importância porque não compreendo. [...] deu inflamação e fiquei preocupada [...] me explicaram que inflamação é normal. [...] eu acho que as pessoas não fazem porque ele (exame) aparece poucas informações. Fui marcar um ginecologista e tinha para daqui a dois meses. [...] na farmácia mostro esse exame [...] nem me exigem receita (SF).

A gente não vê assim com frequência, aconteceu uma epidemia, vacinas, gripe, enfim, nossa, passa em rede nacional, esse não passa (preventivo), você escuta raramente o Ministério da Saúde informando e incentivando fazer [...] já não tem muita informação e se não passa nas rádios e na TV não é tão importante [...] somos levados pela mídia, o que a mídia fala, a sociedade inteira segue [...] então, eles incentivam muito a camisinha, mas o preventivo em si eles falham (MS).

\section{DISCUSSÃO}

Os fatores que podem influenciar as mulheres a realizar o exame 
papanicolau são a idade, o sexo, o local onde o exame é realizado, o estado de saúde, a condição sociocultural e os fatores do sistema de atendimento de saúde. ${ }^{11}$

Observou-se neste estudo, entre as participantes, a presença de adolescentes procurando, não só informações, mas também a realização do exame preventivo. Embora nessa faixa etária a incidência do CCU é baixa, os profissionais da saúde e os da educação devem trabalhar a prevenção sobre doenças sexualmente transmissíveis e os métodos contraceptivos existentes, uma vez que se elas realizarem o exame preventivo, de alguma forma estarão mais próximas das informações em saúde. Com a baixa incidência do câncer em mulheres jovens, existe uma orientação de que mulheres com menos de 25 anos têm baixo risco em relação às mulheres mais maduras. 0 CCU em mulheres até 24 anos é diagnosticado majoritariamente no estágio I. ${ }^{12}$

No relato das mulheres entrevistadas, percebe-se que as mesmas reconhecem a importância do exame preventivo, e que ao adotar esse cuidado anualmente, promovem a sua saúde e bem-estar, tornando assim, possivelmente menor o índice de mortalidade por CCU.

Acredita-se que mulheres, que realizam 0 exame preventivo anualmente, são orientadas e esclarecidas pelos profissionais que atuam na ESF, ou por membros da própria comunidade, o que reforça a importância do exame e, que se forem diagnosticadas precocemente as chances de tratamento e cura do câncer são maiores. Toda mulher que tem ou já teve vida sexual deve submeter-se ao exame preventivo periódico, especialmente as que têm entre 25 e 59 anos. Inicialmente, o exame deve ser feito anualmente. Após dois exames seguidos (com um intervalo de um ano) apresentando resultado normal, o preventivo pode passar a ser feito a cada três anos. ${ }^{1}$

Entre as entrevistadas, percebese a realização periódica dos seus exames, fato que permitiriam interpretar que as mesmas optam pelo cuidado, de forma que possíveis lesões ou alterações sejam detectadas em fase precoce, sendo menores as chances de as mesmas evoluírem para CCU. Mesmo assim, é imprescindível que nas ESF, os profissionais orientem as mulheres sobre a realização periódica do exame preventivo, pois a frequência da realização do exame é um imperativo para reduzir a mortalidade por CCU.

Os resultados do exame preventivo permitem a identificação de alguma alteração, aspectos que implicaria em nova realização do exame após seis meses. Em diferentes casos, podem apresentar alterações mais complexas, assim, a mulher será encaminhada para outros exames mais específicos. Ainda, outros resultados poderão estar relacionados à infecção por Human Papiloma Virus (HPV). 1,11

Diante destes dados, o enfermeiro, profissional capacitado para cuidar destas mulheres, deve aproveitar o momento do exame para deixá-las à vontade para se colocarem, esclarecerem suas dúvidas, além de reforçar a importância da realização periódica do exame e enfatizar 


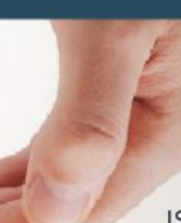

ISSN 2236 - 1987

exposição das genitálias à
sexualidade. ${ }^{15}$

É importante destacar que as mulheres estão convivendo cada vez mais com a incidência de CCU. No ano de 2035, estima-se que 170.080 mulheres com idade igual ou superior a 65 anos desenvolverão este tipo de câncer, se não houver esforços coletivos de ações preventivas na sociedade como um todo. ${ }^{16}$

Entretanto, um dos motivos pelo qual esse número pode aumentar ainda mais é o problema da vergonha e do constrangimento entre as mulheres ao fazerem o exame. Os profissionais de enfermagem da ESF, por meio do cadastramento de sua área adstrita e da avaliação e monitoramento dessa ação programática, podem ter um panorama do número de mulheres, e a partir daí, buscar saber quais as mulheres estão com seus exames em dia, quais estão sem regularidade de frequência na realização do exame e assim elaborar estratégias de busca ativa junto aos agentes comunitários de saúde, na tentativa de convencimento e realização dos exames periódicos das mulheres. Estratégias que envolvam educação da população e difusão de conhecimentos, especialmente, envolvendo a Atenção Básica. Pode mostrar-se o custo-benefício em se tratando dessa preocupante lacuna na saúde brasileira que, no entanto, pode ser substancialmente diminuída. ${ }^{17}$

O medo de ter câncer é um dos principais motivos que frequentemente levam as mulheres a fazer o exame preventivo. As usuárias, que valorizam esse programa de prevenção, sabem que o autocuidado é 
de suma importância para a manutenção da sua saúde. Em fase precoce, o CCU habitualmente não apresenta sintomas. Por isso é tão importante que a mulher faça seu exame periodicamente e não espere que apareçam os sintomas. Dessa forma, a chance de detectar lesões ainda totalmente curáveis é bem maior. ${ }^{15}$

Nos relatos, observa-se que a atitude de prevenção entre as mulheres tem como principal motivo: o medo do diagnóstico, devido a experiências vivenciadas, por crenças e por mitos que envolvem o câncer, pois o preconceito com uma pessoa que tem câncer ainda é grande na sociedade, em que se vive. As pessoas portadoras desta enfermidade sofrem com o problema do medo de não alcançar a cura, mas a maioria dos casos de câncer detectado precocemente tem grandes chances de cura, diminuindo a probabilidade de morte. Esclarece-se à população e aos profissionais da saúde que o CCU é uma patologia de prognóstico bom quando diagnosticado e tratado precocemente. $^{1}$

Entre as mulheres entrevistadas, mesmo com algumas dúvidas, foi possivel identificar que as mesmas associam o exame a um diagnóstico precoce do CCU. No entanto, algumas relatam que o exame preventivo serve para prevenir o câncer, sendo que o exame trata da análise do tecido epitelial realizado no intuito de indagar a existência, ou não, de uma lesão ou uma neoplasia no colo, de forma que a mesma possa ser tratada o mais rápido possível. Destaca-se que explicações e esclarecimentos sobre a coleta de dados precisam ser informadas pela enfermeira que está coletando 0 material, pois desta forma, as mulheres aprendem o que se passa com seu corpo, estimulando assim, o autocuidado.

A ESF possui ações direcionadas à saúde da mulher, desenvolvendo reuniões nas comunidades, orientando a importância da coleta do exame e a busca persistente de mulheres com a ajuda das agentes comunitárias de saúde. O CCU vem apresentando uma elevada taxa de mortalidade no país. Então foi necessário um estudo de adesão ao exame, com a finalidade de que os profissionais da área da saúde pudessem esclarecer esse problema com a população-alvo. ${ }^{15}$

Neste contexto, a relação enfermeiro/paciente fica visível, pois o enfermeiro promove o autocuidado, quando compartilha informações, esclarecendo dúvidas, falando da importância do exame e dos fatores de riscos que o rodeiam. O cuidado da enfermagem dentro da ESF contempla a responsabilidade social que esses profissionais têm com as mulheres e com a sociedade, assim, contribuindo na detecção precoce dessa doença, desenvolvendo ações preventivas e favorecendo a qualidade de vida. ${ }^{9}$

É interessante que o profissional no momento da coleta explique todo o processo do procedimento para a mulher. Principalmente, se for a primeira vez que está experenciando o processo de coleta, pois é nesse momento que a mulher conhece 0 exame, aprende e compreende a sua importância. ${ }^{8,15}$ 


\section{JOURNALOF \\ NURSING \\ ANO HEALTH}

$\mathrm{Na}$ vivência das mulheres deste estudo, não ter o conhecimento sobre o resultado do exame, pode levá-las a elaborar conclusões errôneas, afastando-as do serviço por falta de informação. A maior parte relata não compreender as orientações e ficam na expectativa de explicações mais claras por parte de algum profissional da saúde. Nota-se também, que muitas mulheres não parecem considerar o exame preventivo como um procedimento prático e rotineiro. É necessária uma atuação diferenciada dos profissionais da saúde, principalmente, com as mulheres nas quais se evidencia a falta de informação em relação ao exame preventivo. Deve-se presar por uma atuação com envolvimento e com respeito à intimidade, à privacidade, ao direito de conhecer e poder conversar sobre o CCU e sobre o resultado do exame. ${ }^{14}$

O conhecimento da mulher sobre o CCU apresenta relação com a adesão ao programa preventivo neste estudo. Apesar da maior parte das entrevistadas relatar que o teste de Papanicolaou pode prevenir o CCU, apenas metade respondeu corretamente o intervalo de realização e o momento de início do rastreio. Esses dados sugerem que ações governamentais que visem melhorar o conhecimento público sobre o CCU podem resultar em modelo de atenção mais abrangente, sistemático e efetivo.

O desenvolvimento e a operabilidade da capacidade do autocuidado podem ser afetados pela cultura, padrões de vida, experiências de vida, estado de saúde, sistema
ISSN $2236-1987$

familiar, sexo, idade e escolaridade. Isso leva a pensar sobre a necessidade de acompanhamento e orientação para saber como podem e o que devem fazer para realizar 0 seu autocuidado. ${ }^{14-17}$

É necessário garantir que a mulher tenha acesso a essas informações, e que elas também as compreendam, como a busca persistente das que faltam para a realização do exame ou com campanhas e ações de incentivo como força tarefa ou uma operação de cidadania, para mobilizar essas pessoas e tentar com que elas compareçam para ofertar a assistência. ${ }^{18}$

Outro fator importante para o sucesso, não só da adesão das mulheres na realização do exame, bem como o retorno para se obter o resultado, é a responsabilidade do profissional enfermeiro em estabelecer o diálogo e os possíveis intercâmbios aos serviços, configurando assim, o cuidado integral. Nesta perspectiva, a responsabilidade de realizar o cuidado integral, estabelecendo vínculo, valorizando 0 indivíduo, não se detendo a um único profissional, mas ao conjunto de profissionais que compõem a equipe de saúde. ${ }^{19}$

O desconhecimento do resultado, muitas vezes, pode originar entre as mulheres uma interpretação pouco fidedigna acerca do resultado do exame, fazendo com que as mesmas não retornem à unidade de saúde por medo ou receio. Observou-se que as mulheres entrevistadas nesta pesquisa, que realizam periodicamente o exame preventivo, sabem interpretar com propriedade os resultados, enquanto que outras que realizam o exame 


\section{ISSN 2236 - 1987}

esporadicamente apresentam parcial ou total desconhecimento sobre o resultado. Fato que reforça a importante tarefa do profissional enfermeiro da ESF na busca do esclarecimento das mulheres sobre, não só a realização do exame, mas também do conhecimento do teor do resultado do mesmo.

\section{CONSIDERAÇÕES FINAIS}

0 vínculo entre o profissional enfermeiro e as usuárias dos serviços de saúde ameniza os vários sentimentos negativos envolvidos no processo de realização do exame preventivo. 0 oferecimento do preventivo no serviço de saúde não é suficiente. 0 estabelecimento de vínculos de confiança entre as partes também deve ser priorizado.

Embora o Ministério da Saúde tenha boa inserção no programa de saúde da mulher, mesmo assim, ainda o número de casos de CCU continua aumentando a cada ano. 0 desconhecimento pelas mulheres da forma em que o exame é realizado, as doenças que podem ser detectadas através dele, é que causam o descaso do próprio.

0 enfermeiro tem 0 papel fundamental na coleta do exame preventivo, uma vez que tem a função de estar informando as mulheres que realizam o exame, tratando-as com ética, educação, respeito e profissionalismo. A partir disso, as mulheres certamente sentem-se mais confiantes em fazer o exame. Estar divulgando as informações adequadas e claras para que as pacientes tenham uma boa referência, e retornem a fazer o exame na certeza e confiança de que o profissional é a pessoa mais qualificada para desenvolver a técnica desde o início da coleta até a entrega do resultado. Sendo assim, se a mulher se sentir acolhida e informada, desenvolverá confiança nos profissionais e no centro de atendimento, aumentando, consequentemente, 0 número de mulheres atendidas nos serviços.

\section{Considera-se} desenvolvimento de estudos semelhantes em distintas realidades, tonem-se necessários, uma vez que permitirão identificar as dificuldades apresentadas pelas mulheres para realizar o exame preventivo e ter conhecimento dos resultados do mesmo, tendo em vista que este estudo foi desenvolvido com um número reduzido de participantes.

Vale ressaltar que na temática de CCU se tem muito ainda que se avançar por meio de pesquisas, principalmente, que possam contribuir com o conhecimento, práticas para adesão e educação e saúde e o desenvolvimento do combate desta doença que atinge a todos.

\section{REFERÊNCIAS}

1. World Health Organization (WHO). ICO Information Centre on HPV and Cervical Cancer (HPV Information Centre). Summary report on HPV and cervical cancer statistics in Brazil [Internet]. [acesso em 2014 jan 01]. Disponível em: http: / /www.hpvcentre.net

2. Instituto Nacional do Câncer (BR). Controle do Câncer do Colo Uterino [Internet]. 2016 [acesso em 2012 dez 13]. Disponível em: 


\section{JOURNALOF \\ NURSING \\ ANO HEALTH}

http://www2.inca.gov.br/wps/wcm/c onnect/acoes_programas/site/home/ nobrasil/programa_nacional_controle_ cancer_colo_utero/conceito_magnitud e

3. Navarro C, Fonseca AJ, Sibajev A, Souza CIA, Araújo DS, Teles DAF, et al. Cobertura do rastreamento do câncer de colo de útero em região de alta incidência. Rev saude publica. 2015 fev;49(17):1-8.

4. Instituto Nacional de Câncer (BR). Estimativa 2016. Incidência do Câncer no Brasil. Rio de Janeiro: INCA [Internet]. 2015 [acesso em 2013 jan 28]. Disponível em: http://www.inca.gov.br/estimativa/2 016/estimativa-2016-v11.pdf

5. Arzuaga-Salazar MA, Souza ML, Lima VLA. El cáncer de cuello de útero: un problema social mundial. Rev cubana enferm. 2012 mar;28(1):63-73.

6. Tomasi E, Oliveira TF, Fernandes PAA, Thumé E, Silveira DS, Siqueira FV, et al. Estrutura e processo de trabalho na prevenção do câncer de colo de útero na Atenção Básica à Saúde no Brasil: Programa de Melhoria do Acesso e da Qualidade -PMAQ. Rev bras saude matern infant. 2015 abr/jun;15(2):171-80.

7. Melo MCSC, Vilela F, Salimena AMO, Souza IEO. O enfermeiro na prevenção do câncer do colo do útero: o cotidiano da Atenção Primária. Rev bras cancerol. 2012 jul/set;58(3):389-98.

8. Trentini $M$, Paim L. Pesquisa convergente assistencial: um desenho que une o fazer e o pensar na pratica assistencial em saúde-enfermagem. $2^{a}$ ed. Florianópolis: Insular; 2004.
ISSN 2236 - 198

9. Mistura C, Mistura C, Silva RCC, Sales JRP, Melo MCP, Sarmento SS. Papel do enfermeiro na prevenção do câncer de colo uterino na estratégia saúde da família. Rev contexto saude. 2011 jan/jun;10(20):1161-4.

10. Bardin L. Análise de conteúdo. $6^{a}$ ed. São Paulo: Edições 70; 2011.

11. Ministério da Saúde (BR). Conselho Nacional de Saúde. Resolução 466, de 12 de dezembro de 2012: diretrizes e normas regulamentadoras de pesquisa envolvendo seres humanos. Brasília; 2012.

12. Andrade MS, Almeida MMG, Araújo TM, Santos KOB. Fatores associados a não adesão ao Papanicolau entre mulheres atendidas pela Estratégia Saúde da Família em Feira de Santana, Bahia, 2010. Epidemiol serv saude. 2014 jan/mar;23(1):111-20.

13. Instituto Nacional do Câncer (BR). Diretrizes brasileiras para o rastreamento do câncer do colo do útero/ Instituto Nacional de Câncer. Coordenação Geral de Ações Estratégicas. Divisão de Apoio à Rede de Atenção Ontológica. Rio de Janeiro: INCA; 2011.

14. Nery AA. Concepção de saúde: visão de adolescentes do ensino fundamental de um município da Bahia. Revista saúde com. 2009 jan/mar;5(1):17-30.

15. Oliveira AF, Cunha CLF, Viégas IF, Figueiredo IS, Brito LMO, Chein MBC. Estudo sobre a adesão ao exame citopatológico de papanicolau em um grupo de mulheres. Rev pesq saude. 2010 jan/abr;111(1):32-7.

16. Gomes CHR, Silva JA, Ribeiro JA, Penna RMM. Câncer Cervicouterino: 


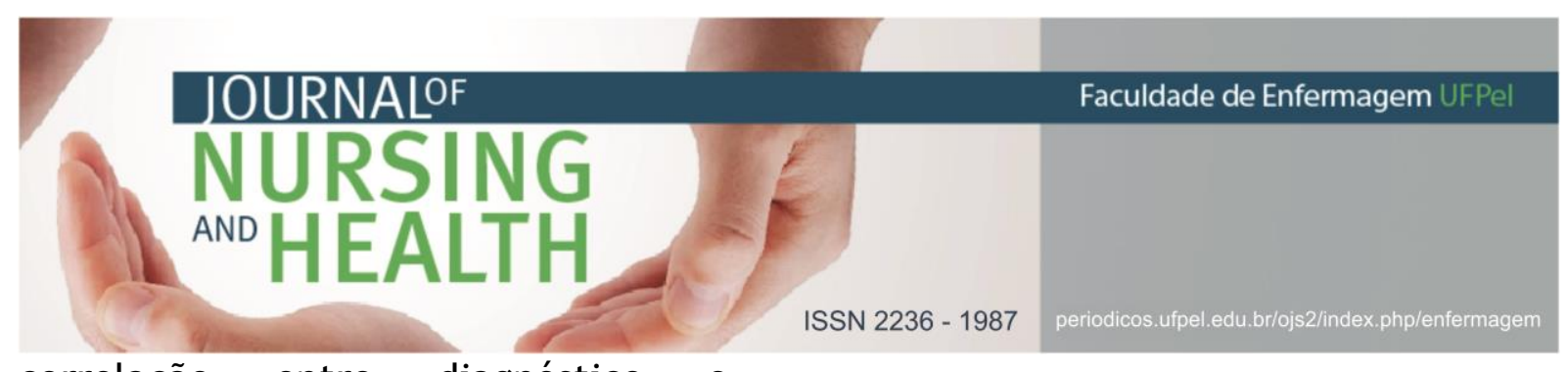

correlação entre diagnóstico e realização prévia de exame preventivo em serviço de referência no norte de Minas Gerais. Rev bras cancerol. 2012 jan/mar;58(1):41-4.

17. Ferreira MLSM. Motivos que influenciam a não-realização do exame de papanicolaou segundo a percepção de mulheres. Esc Anna Nery. 2009 abr/jun;13(2):378-84.

18. Peretto $M$, Drehmer LBR, Bello HMR. O não comparecimento ao exame preventivo do câncer de colo uterino: razões declaradas e sentimentos envolvidos. Cogitare enferm. 2012 jan/mar;17(1):29-36.

19. Rocha MGL, Linard AG. Percepções de mulheres sobre integralidade no contexto das ações de prevenção do câncer cérvico-uterino. Rev RENE. 2016 set/out;17(5):676-83.

Data de submissão: 15/03/2016

Data de aceite: 15/01/2017

Data de publicação: 30/08/2017 